\title{
Rat islet cell aggregates are superior to islets for transplantation in microcapsules
}

\author{
E. S. O'Sullivan • A. S. Johnson • A. Omer • \\ J. Hollister-Lock • S. Bonner-Weir • C. K. Colton • \\ G. C. Weir
}

Received: 28 September 2009 / Accepted: 9 December 2009 / Published online: 26 January 2010

(C) Springer-Verlag 2010

\begin{abstract}
Aims/hypothesis Islet transplantation is a promising treatment for type 1 diabetes but is hampered by a shortage of donor human tissue and early failure. Research on islet cell transplantation includes finding new sources of cells and immunoisolation to protect from immune assault and tumourigenic potential. Small islet cell aggregates were studied to determine if their survival and function were superior to intact islets within microcapsules because of reduced oxygen transport limitation and inflammatory mediators.

Methods Islet cell aggregates were generated by dispersing rat islets into single cells and allowing them to re-aggregate in culture. Rat islets and islet cell aggregates were encapsulated in barium alginate capsules and studied when cultured in low $(0.5 \%$ or $2 \%)$ or normal $(20 \%)$ oxygen, or transplanted into mice.
\end{abstract}

E. S. O'Sullivan and A. S. Johnson contributed equally to this study.

Electronic supplementary material The online version of this article (doi:10.1007/s00125-009-1653-8) contains supplementary material, which is available to authorised users.

E. S. O'Sullivan · A. Omer · J. Hollister-Lock $\cdot$ S. Bonner-Weir $\cdot$

G. C. Weir $(\bowtie)$

Section on Islet Transplantation and Cell Biology,

Research Division, Joslin Diabetes Center,

One Joslin Place,

Boston, MA 02215, USA

e-mail: gordon.weir@joslin.harvard.edu

E. S. O’Sullivan · A. Omer $\cdot$ S. Bonner-Weir · G. C. Weir

Department of Medicine, Harvard Medical School,

Boston, MA, USA

A. S. Johnson • C. K. Colton

Department of Chemical Engineering,

Massachusetts Institute of Technology,

Cambridge, MA, USA
Results Encapsulated islet cell aggregates were able to survive and function better than intact islets in terms of oxygen-consumption rate, nuclei counts, insulin-to-DNA ratio and glucose-stimulated insulin secretion. They also had reduced expression of pro-inflammatory genes. Islet cell aggregates showed reduced tissue necrosis in an immunodeficient transplant model and a much greater proportion of diabetic xenogeneic transplant recipients receiving islet cell aggregates (tissue volume of only 85 islet equivalents) had reversal of hyperglycaemia than recipients receiving intact islets.

Conclusions/interpretation These aggregates were superior to intact islets in terms of survival and function in lowoxygen culture and during transplantation and are likely to provide more efficient utilisation of islet tissue, a finding of importance for the future of cell therapy for diabetes.

Keywords Alginate - Aggregates - Beta cell .

Bioengineering capsules $\cdot$ Diabetes $\cdot$ Hypoxia $\cdot$ Islet cell .

Oxygen $\cdot$ Transplantation

$\begin{array}{ll}\text { Abbreviations } \\ \text { GSIS } & \text { Glucose-stimulated insulin secretion } \\ \text { IE } & \text { Islet equivalents } \\ \text { IPGTT } & \text { Intraperitoneal glucose tolerance test } \\ \text { KRBH } & \text { Krebs buffered HEPES } \\ \text { OCR } & \text { Oxygen consumption rate }\end{array}$

\section{Introduction}

Islet transplantation has the potential to reverse diabetes and become a superior alternative to the exogenous administration of insulin, but it remains an experimental procedure facing 
multiple obstacles. There is a great shortage of donor islet tissue, and immunosuppressive therapies pose considerable risk to recipients and are harmful to the transplanted islets.

Microencapsulation confers immunoprotection to transplanted islets, which may make it possible to avoid the need for immunosuppressive therapy [1-3]. There has been impressive recent progress in finding a new source of sufficient numbers of healthy beta cells, with attractive potential sources being embryonic stem cells, induced pluripotent cells and porcine islet cells $[4,5]$. However, their immunogenicity will likely remain an obstacle, hence the importance of immunobarrier technology. In turn, there is concern that these cells may harbour tumourigenic potential; immunoisolation would have the added role of protecting the host.

In this study, we have used a novel model system to demonstrate the superiority of using small aggregates of islet cells in microcapsules. We expect that this general approach will be valuable whatever immunobarrier devices might be used for the cell sources of the future $[6,7]$. We hypothesise that small aggregates of islet cells have advantages for transplantation by being less susceptible to hypoxic death and release of pro-inflammatory molecules. When islets are transplanted, $50 \%$ of the tissue may be lost in the first few days [8]; this is thought likely to be due to hypoxic death before vascularisation develops. Small islets function better than large islets when transplanted $[9,10]$, which is consistent with relatively less hypoxia and the subsequent necrosis that develops in the centres of cultured large islets $[11,12]$. Another concern is that hypoxic and necrotic islet cells are pro-inflammatory [13, 14], and cell debris and other factors released could elicit a host immune response. Single cells dispersed from whole islets can reaggregate to form islet-like structures [15]. These aggregates, when transplanted, can reverse hyperglycaemia as effectively as islets [16]. Mathematical modelling indicates that smaller islet cell aggregates should survive and function better than whole islets in capsules because of shorter diffusion distances within oxygen-consuming tissue [17-19], which leads to increased oxygen levels, reduced necrosis and increased insulin-secretion capability [12]. Similar results can be expected for other encapsulation materials and geometries and other islet or beta cell tissue types.

\section{Methods}

Animals Male Lewis or Sprague-Dawley rats, 200-250 g (Harlan Sprague-Dawley, Madison, WI, USA) were used as islet donors. Lewis rats and BALB/c mice (Taconic, Hudson, NY, USA) were recipients. (Lewis-to-Lewis normoglycaemic syngeneic transplants for histology experiments, Sprague-Dawley rat islets for in vitro experiments and xenogeneic transplants to diabetic BALB/c mice). Diabetes was induced in mice with intraperitoneal injection of streptozotocin (Sigma Aldrich), $250 \mathrm{mg} / \mathrm{kg} \mathrm{10-14} \mathrm{days}$ before transplantation. Diabetes was defined as fed glucose levels above $19.6 \mathrm{mmol} / \mathrm{l}$, and normoglycaemia as two consecutive measurements below $11.2 \mathrm{mmol} / 1$. Animal experiments were approved by the Joslin Institutional Animal Care and Use Committee.

Islet isolation, dispersion, and re-aggregation Rat islets were isolated, placed in culture for 1 day and dispersed with trypsin and DNAse as previously described $[15,20]$. The medium was RPMI 1640 supplemented with $10 \%$ (vol./ vol.) fetal bovine serum, $100 \mathrm{U} / \mathrm{ml}$ penicillin, and $100 \mu \mathrm{g} /$ $\mathrm{ml}$ streptomycin (Mediatech, Herdon, VA, USA). The depth was $2.5 \mathrm{~mm}$ and density lower than 30 islet equivalents (IE) $/ \mathrm{cm}^{2}$ to avoid oxygen limitation [21, 22]. Cells were counted with a haemocytometer; 500,000 cells were placed into $60 \mathrm{~mm}$ diameter dishes (ultra low attachment), and cultured overnight to allow the cells to re-aggregate during the following day. The average diameter of the aggregates was $39 \pm 6.5 \mu \mathrm{m}$, determined from photographs of capsules ( $n=20$, three experiments, 220 aggregates in total); five to eight photos were taken at different focal planes through each capsule, and the area of tissue in each aggregate, $A_{\text {agg }}$, was measured using pixel-counting software (IP lab, BD Biosciences, San Jose, CA, USA). The area-average diameter, $d_{\mathrm{agg}}$, was derived from these measurements assuming a circular shape $\left(A_{\mathrm{agg}}=\pi d_{\mathrm{agg}}{ }^{2} / 4\right)$. The number of cells in aggregates was quantified in triplicate with nuclei counting as described below.

Microencapsulation Two days after islet isolation, microcapsules of alginate with high guluronic acid content (Pronova SLG 100, FMC Polymer, Drammen, Norway) at a concentration of $1.5 \%(\mathrm{wt} / \mathrm{vol}$.) in $0.9 \%$ (wt/vol.) $\mathrm{NaCl}$ were produced using an electrostatic droplet generator (Pronova) by extrusion of the tissue-alginate suspension (islets or aggregates) through a needle into $20 \mathrm{mmol} / 1 \mathrm{BaCl}_{2}$ solution. The average microcapsule diameter was $422 \pm$ $9 \mu \mathrm{m}(n=100$ islet- and aggregate-containing capsules in each of five experiments).

Culture of encapsulated islet cells For culture in 20\% oxygen, capsules were placed in $100 \mathrm{~cm}^{2}$ flasks (PR-AY-50017-5, Wilson Wolf Manufacturing, New Brighton, MN, USA) with silicone rubber bottoms that provided high oxygen permeability $[21,23]$. The medium was RPMI 1640 supplemented with $10 \%$ (vol./vol.) fetal bovine serum, $100 \mathrm{U} / \mathrm{ml}$ penicillin, and $100 \mu \mathrm{g} / \mathrm{ml}$ streptomycin (Mediatech). The depth was $2.5 \mathrm{~mm}$, and density lower than $30 \mathrm{IE} / \mathrm{cm}^{2}$ to avoid oxygen limitation [11, 24]; flasks were placed in an incubator with $5 \% \mathrm{CO}_{2}$ balanced with air, at $37^{\circ} \mathrm{C}$. 
Capsules cultured at reduced oxygen were placed in 24 well plates having silicone rubber bottoms (PR-AY-70004) with a $10 \mathrm{~mm}$ culture medium depth and density of 50-200 IE $/ \mathrm{cm}^{2}$. Plates were placed in a humidified incubator (Xvivo Incubation System, Biospherix, Redfield, NY, USA) controlled to be at $0.5 \%$ or $2 \% \mathrm{O}_{2}$ and $5 \%$ $\mathrm{CO}_{2}$ balanced with $\mathrm{N}_{2}$. Capsules for transplantation were cultured in Ultraculture medium containing $20 \mathrm{mmol} /$ 1 glucose (Biowittaker, Wakerville, MD, USA), supplemented with $2 \mathrm{mmol} / \mathrm{l}$ L-glutamine, $100 \mathrm{U} / \mathrm{ml}$ penicillin and $100 \mu \mathrm{g} / \mathrm{ml}$ streptomycin.

Oxygen consumption rate (OCR) OCR was measured as previously described [22]. Microcapsules were resuspended in DMEM without phenol red, containing $25.2 \mathrm{mmol} / 1$ glucose supplemented with $0.6 \mathrm{~g} / \mathrm{l} \mathrm{L}$-glutamine, $100 \mathrm{U} / \mathrm{ml}$ penicillin, $100 \mu \mathrm{g} / \mathrm{ml}$ streptomycin and $10 \mathrm{mmol} / \mathrm{l} \mathrm{HEPES}$ (Mediatech) without serum, and added to a $200 \mu \mathrm{l}$ stirred titanium chamber (MicroOxygen Uptake System FO/SYSZ-P250, Instech Laboratories, Plymouth Meeting, PA, USA) maintained at $37^{\circ} \mathrm{C}$. The time-dependent partial pressure of $\mathrm{O}_{2}$ $\left(\mathrm{O}_{2}\right)$ within the chamber was recorded with a fluorescencebased oxygen sensor (Ocean Optics, Dunedin, FL, USA), and data at high $p \mathrm{O}_{2}$ were fitted to a straight line with slope $\Delta p \mathrm{O}_{2} / \Delta t$. OCR was evaluated from $\mathrm{OCR}=V_{\mathrm{ch}} \alpha_{\mathrm{s}}\left(\Delta p \mathrm{O}_{2} / \Delta t\right)$, where $V_{\text {ch }}$ is chamber volume and $\alpha$ is the Bunsen solubility coefficient for oxygen dissolved in the medium.

Capsule dissolution Measurements of nuclei counts, insulin, DNA and alginate required capsule dissolution. After OCR measurement, $800 \mu \mathrm{l}$ of $100 \mathrm{mmol} / \mathrm{l}$ tetrasodium EDTA (pH 8) was added to approximately $250 \mu \mathrm{l}$ of capsule suspension in DMEM recovered from the OCR chamber and subsequent washes, placed in an incubator at $37^{\circ} \mathrm{C}$ for $1 \mathrm{~h}$, and mixed by vortexing every $30 \mathrm{~min}$. Alginate concentration was assayed using Dimethyl Methylene Blue dye (Sigma Aldrich, St Louis, MO, USA), which binds to alginate [25]. The ratio of absorbance at wavelengths of 520 and $650 \mathrm{~nm}$ increased linearly with alginate concentration. Capsule volume in the sample was calculated from alginate concentration in the original capsule and fluid volume and alginate concentration in the sample. For the purpose of comparing OCR values and nuclei counts before and after culture, measurements of these quantities were divided by capsule volume. This procedure improved the precision of OCR and tissue recovery estimates by minimising the effects of error in sampling capsules from suspension.

Glucose-stimulated insulin secretion (GSIS) Encapsulated islets or aggregates were suspended in Krebs buffered HEPES (KRBH) with 0.1\% (wt/vol.) BSA, pH 7.4, containing $2.8 \mathrm{mmol} / \mathrm{l}$ glucose. Pre-culture and $20 \% \mathrm{O}_{2}$ culture samples were kept at $37^{\circ} \mathrm{C}$ in humidified air and $5 \%$ $\mathrm{CO}_{2}$ for the study. Low-oxygen samples were kept in a controlled oxygen environment (Xvivo Incubation System) at $37^{\circ} \mathrm{C}$ in humidified $2 \%$ or $0.5 \%$ oxygen with $5 \% \mathrm{CO}_{2}$, balanced with $\mathrm{N}_{2}$, which allowed GSIS to be performed without exposing the tissue to atmospheric oxygen. Five $1 \mathrm{ml}$ aliquots with approximately 20 microcapsules containing islets or aggregates were pre-incubated in $\mathrm{KRBH}$ containing $2.8 \mathrm{mmol} / \mathrm{l}$ glucose at $20 \%$ oxygen for $1 \mathrm{~h}$ in 24 well plates with plastic bottoms (BD Biosciences, Rockville, MD, USA) or at $2 \%$ or $0.5 \%$ in the 24 well plates with silicone rubber bottoms that were used for low-oxygen culture. Insulin secretion was then assessed by consecutive incubations of $1 \mathrm{~h}$ in $\mathrm{KRBH}$ containing $2.8 \mathrm{mmol} / 1$ glucose and $16.8 \mathrm{mmol} / 1$ glucose.

Xenogeneic transplants These were done to examine the reversibility of diabetes. Two days after isolation of islets from Sprague-Dawley rats, aggregates and islets were encapsulated. Shortly thereafter, islet- and aggregatecontaining capsules were sampled in triplicate, the total cell number was quantified by nuclei counting, and the tissue volume was estimated using 1560 cells per IE [26]. The remaining tissue was cultured overnight in uncoated tissue-culture flasks with serum-free Ultraculture medium in a standard humidified incubator using $37^{\circ} \mathrm{C}$ in $20 \% \mathrm{O}_{2}$, $5 \% \mathrm{CO}_{2}$ balanced with nitrogen. On day 3 , aliquots of the remaining capsules suspended in culture media were prepared to correspond to $375,250,125$ or 85 IE by collecting all of the capsules, dividing the number of capsules by volume of medium and carefully pipetting up and down to ensure capsules remained suspended while preparing aliquots. They were then transplanted intraperitoneally in diabetic $\mathrm{BALB} / \mathrm{c}$ or ICR/SCID mice under ketamine/xylazine anaesthesia (by intraperitoneal injection) through a 5-10 $\mathrm{mm}$ midline incision using a sterile plastic transfer pipette (Fisher Scientific, Pittsburgh, PA, USA). The 85 IE recipients received an average of 370 capsules containing islets or 354 capsules containing aggregates (this number was determined from $\mathrm{IE} / \mathrm{ml}$ measurements taking into account the average capsule volume that was calculated from their average diameter).

Syngeneic normoglycaemic transplants To assess viability in a transplant situation, encapsulated islets or islet cell aggregates of Lewis rat origin were injected into the peritoneal cavity of Lewis rats using the same approach as that used for the mice. Capsules were retrieved 2 weeks after transplantation by laparotomy and peritoneal lavage and prepared for histology.

Other measurements The methods for: measurement of nuclei counts, insulin and DNA content; expression of 
$M c p-1$ (also known as Ccl2), F3, Vegf (also known as Vegfa), iNos (also known as Nos2), Glut2 (also known as Slc2a2) and Ins 1 in islets and aggregates with PCR; histology to assess necrosis; immunostaining insulin and glucagon to determine cell composition; and for intraperitoneal glucose tolerance testing can be found in the Electronic supplementary material (ESM).

Statistics Data are expressed as mean \pm SEM unless indicated otherwise. Statistical significance was determined by one-way ANOVA followed by Tukey test, Student's $t$ test (two-tailed) or Fisher exact test. The Kolmogorov-Smirnov or Shapiro-Wilk test was used to ensure the data were normally distributed.

\section{Results}

Tissue loss in the dispersion and re-aggregation process $A$ fter the islets were exposed to trypsin/DNAse in preliminary experiments $(n=2)$ for $15 \mathrm{~min}, 83 \pm 22 \%$ of cells were recovered. When the cell number was again quantified by nuclei counts after re-aggregation for $16 \mathrm{~h}$ (a total of about 2 days culture time), $55 \pm 5 \%$ were recovered. For comparison, after intact rat islets were cultured under normoxic conditions for 2 days, $63 \%$ of the tissue was recovered as determined by nuclei counts [26].

Necrosis in cultured encapsulated islets Most tissue appeared healthy in sections of islet- and aggregatecontaining capsules shortly after encapsulation (Fig. 1a,b). After 2 day culture in $2 \%$ oxygen, cells in the centre of some islets stained lightly with Toluidine Blue, indicating necrosis (Fig. 1c), whereas aggregates appeared uniformly healthy (Fig. 1d). The sections shown are representative of sections from three separate experiments before and after low-oxygen culture, including 119 islets cultured in $2 \%$ oxygen. The fractional area of islet tissue occupied by necrotic centres after $2 \%$ oxygen culture averaged $6.0 \pm$ $5.1 \%(n=3)$. Similar results were obtained in two experiments with $0.5 \%$ oxygen. The necrotic areas were much larger in some islets (up to $16 \%$ fractional necrotic area), while some sections showed no necrosis. These observations depended on the plane through which the islets were sectioned, as more central sections were more likely to show necrosis (Fig. 1c). In contrast, with examination of equivalent areas of encapsulated aggregates, central necrosis was not observed except in one islet-sized aggregate.

Viable islet tissue recovery as determined by OCR OCR measurements of encapsulated Sprague-Dawley rat islets were performed on the day of encapsulation and again after
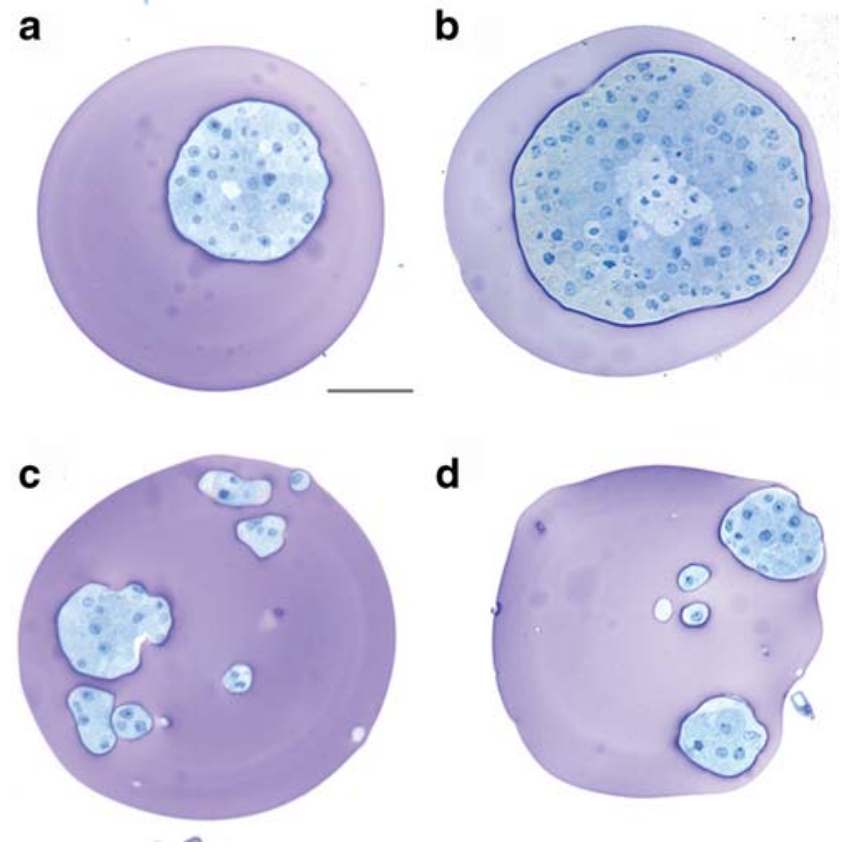

Fig. 1 Histology of encapsulated islets and islet cell aggregates before $(\mathbf{a}, \mathbf{b})$ and after $(\mathbf{c}, \mathbf{d}) 2$ day culture in $2 \%$ oxygen. Islets, a, c; aggregates, $\mathbf{b}, \mathbf{d}$. Pale areas of staining represent necrotic cells in the islet centre. Scale bar, $50 \mu \mathrm{m}$

2 day culture under normal- $(20 \%)$ or low-oxygen $(0.5 \%$ or $2 \%$ ) conditions. After measurement, the alginate was dissolved and the suspension analysed for nuclei counts and insulin, DNA and alginate concentration. The amount of viable tissue in a sample was directly proportional to the sample OCR, and the fractional viable tissue recovery was taken as equal to the OCR recovery, defined as OCR in the sample after culture divided by OCR in the sample before culture, both quantities normalised to the same unit capsule volume (Fig. 2a). Under $20 \%$ oxygen, the fraction of viable tissue did not decline for either aggregates or islets; for unclear reasons, there was a modest increase in the aggregates. Culture in $2 \%$ oxygen resulted in maintenance of pre-culture levels of viable tissue in aggregates, but only $61 \%$ of pre-culture viable tissue remained $(p<0.01)$ for whole islets. Culture in $0.5 \%$ oxygen resulted in a similar loss of viable islet tissue and a non-significant decline in amount of viable aggregate tissue.

A theoretical mathematical model was developed to simulate the culture of islet tissue in $2 \%$ oxygen (see ESM). The results of the model predicted an OCR recovery for islets of 53\% with virtually no loss for aggregates, in reasonable agreement with experimental data.

Tissue recovery as determined by nuclei counts In Fig. 2b, tissue recovery, analogous to OCR recovery, reflects the number of cells containing an intact nucleus that remained 

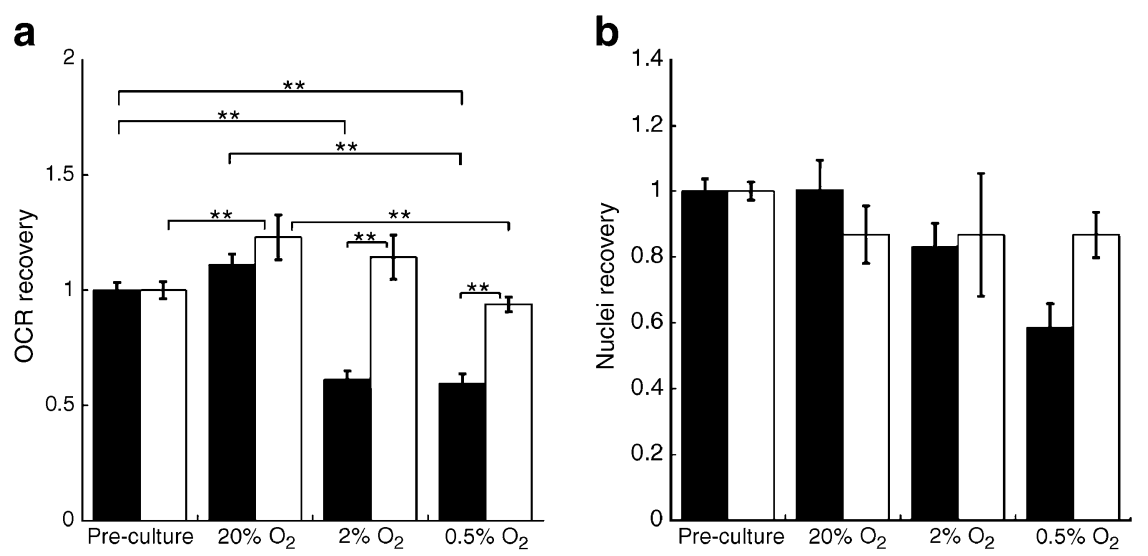

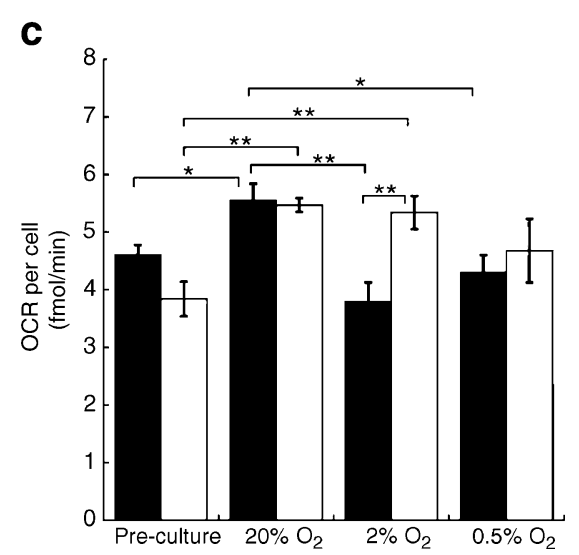

Fig. 2 a OCR recovery, defined as the $\mathrm{OCR} / \mathrm{ml}$ capsule volume measured in a sample at the end of the culture period divided by the same quantity measured prior to culture (pre-culture), $p<0.0001$ (ANOVA). b Tissue recovery, defined as the number of nuclei $/ \mathrm{ml}$ capsule volume measured in a sample at the end of the culture period divided by the same quantity measured prior to culture. $\mathbf{c}$ OCR per cell measured before and after culture, $p<0.001$ (ANOVA). Islets (black bars) and aggregates (white bars) were cultured for 2 days in $20 \%(n=$ $15), 2 \%(n=9)$ or $0.5 \%(n=6)$ oxygen (three replicates for each of five, three and two separate islet preparations, respectively). The Tukey test was performed after ANOVA to compare the individual groups. Differences were found at the level of $p<0.05$ for OCR recovery (a): islets pre-culture vs $2 \%$ oxygen, islets pre-culture vs $0.5 \%$ oxygen, islets $20 \%$ vs $2 \%$ oxygen, islets $20 \%$ vs $0.5 \%$ oxygen, and islets vs aggregates in $2 \%$ oxygen; for OCR per cell (c): islets $20 \%$ vs $0.5 \%$ oxygen, aggregates pre-culture vs $20 \%$ oxygen, islets $20 \%$ vs $2 \%$ oxygen. Student's $t$ test was also performed to compare individual groups: ${ }^{*} p<0.05, * * p<0.01$ after culture relative to the number present prior to culture. After culture in $20 \%$ or $2 \%$ oxygen, there was no difference in tissue recovery between islets and aggregates. However, there was loss of tissue in the islets cultured at $0.5 \%$ oxygen when compared with pre-culture values $(59 \%)$, but only modest loss of tissue in the aggregate capsules (87\% of preculture values). The relative total tissue losses at low oxygen were not as dramatic as the loss of viable tissue determined by OCR, which may result from surviving impaired cells.

Tissue viability as determined by OCR per cell OCR per cell is a measure of the relative viability of tissue in a sample [27]. The initial value for both islets and aggregates, about $4 \mathrm{fmol} / \mathrm{min}$ (Fig. 2c), is at the upper end of the range of values reported for freshly isolated islets [26], indicating that the islet preparation had relatively high viability. Values for aggregates and islets were similar following culture in $20 \% \mathrm{O}_{2}$ and $0.5 \% \mathrm{O}_{2}$, but values for islets were significantly lower after culture in $2 \%$ oxygen $(p<0.05)$.

Insulin:DNA ratio as an index of islet viability The ratio of insulin to DNA content is considered an index of beta cell viability because healthy beta cells store large amounts of insulin. This ratio decreased markedly in islets cultured in $0.5 \%$ oxygen compared with $20 \%$ oxygen for 2 days, in contrast to no decline in aggregates (Fig. 3a). The ratio did not decline in either tissue configuration after culture in $2 \%$ oxygen for 2 days, indicating that this relatively low oxygen concentration is compatible with adequate insulin storage in both tissue configurations.
GSIS On the day of encapsulation, GSIS was indicative of very healthy beta cells for both islets and islet cell aggregates with low insulin release at $2.8 \mathrm{mmol} / \mathrm{l}$ glucose and a much higher rate of secretion at $16.8 \mathrm{mmol} / \mathrm{l}$ (Fig. 3b). This normal pattern of insulin secretion was preserved with both tissue configurations after 2 day culture in $20 \%$ oxygen but became abnormal after 2 days at $2 \%$ oxygen, as evidenced by inappropriately high basal insulin release. There was no difference in insulin output between low and high glucose with islets, whereas islet cell aggregates showed differentially increased secretion to high glucose. Consequently, at $2 \%$ oxygen, insulin content was preserved while differential insulin secretion was moderately impaired in aggregates and eliminated in islets. When islets or aggregates were cultured at $0.5 \%$ oxygen, insulin secretion was not responsive to glucose for either tissue configuration (data not shown). The theoretical model (see ESM) predicted that the fractional recovery of normal insulin secretory function after culture would be $36 \%$ for islets and $83 \%$ for aggregates after culture in $2 \%$ oxygen.

Quantification of beta cells vs non-beta cells Ratios of beta to non-beta cells were determined for encapsulated islets and islet cell aggregates before and after culture. Prior to culture and immediately after encapsulation, islets and aggregates were composed of a similar proportion of beta cells, $77 \pm 4 \%$ and $74 \pm 1 \%$, respectively. However, after culture for 2 days in $2 \%$ oxygen, the relative contribution of beta cells in both tissue configurations rose similarly to $82 \pm$ $8 \%$ and $83 \pm 3 \%$, respectively. After culture in $20 \%$ oxygen, the aggregates had a significantly smaller beta cell 


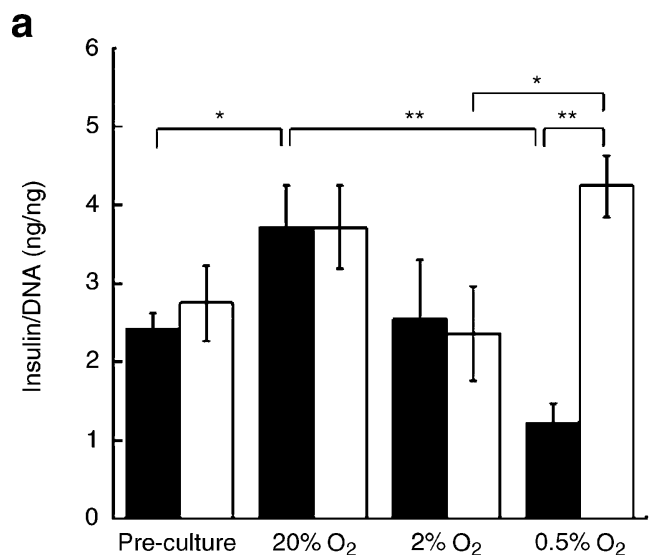

b

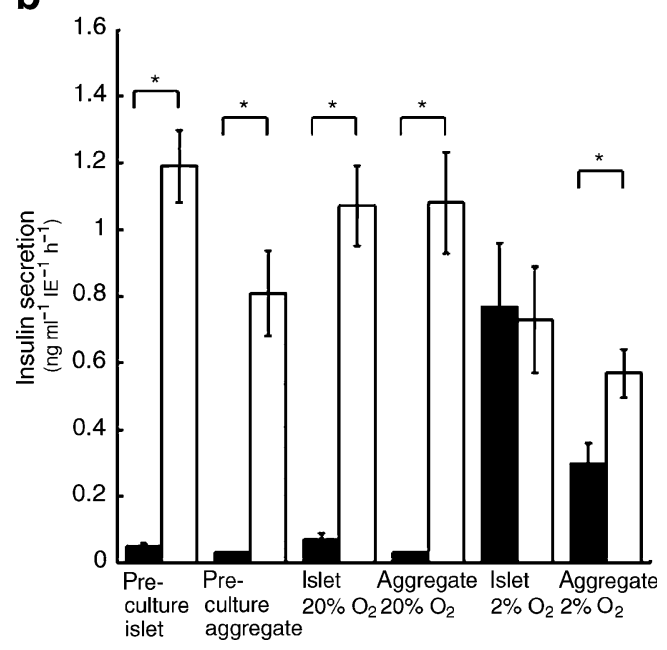

Fig. 3 a Ratio of insulin to DNA content in encapsulated islets (black bars) and aggregates (white bars) on the day of encapsulation (preculture) and after 2 day culture in $20 \%(n=12$, three replicates from each of four separate islet preparations), $2 \%$ or $0.5 \%$ oxygen, $p<0.05$ ANOVA $(n=6$, three replicates from each of two separate islet preparations). The Tukey test was performed after ANOVA to compare the individual groups. Differences were found at the level of $p<0.05$ for: aggregates $2 \%$ vs $0.5 \%$ oxygen, islets $20 \%$ vs $0.5 \%$ oxygen, and islets vs aggregates in $0.5 \%$ oxygen. b GSIS from encapsulated islets or aggregates in low glucose $(2.8 \mathrm{mmol} / \mathrm{l}$, black bars) and high glucose (16.8 mmol/1, white bars) immediately after encapsulation prior to culture and then after 2 day culture in $20 \%$ or $2 \%$ oxygen $(n=10$, five replicates from each of two separate islet preparations). A Student's $t$ test was also performed to compare individual groups: $* p<0.05, * * p<0.01$

component $(72 \pm 2 \%)$ than the islets $(83 \pm 1 \%, p<0.01)$. We have no definitive explanation for these changes at $20 \%$ oxygen, but they did not lead to measurable differences in insulin:DNA ratios.

Gene expression Pro-inflammatory genes $M c p-1$ and F3 were expressed at lower levels in aggregates than in whole islets $(36 \pm 9 \%$ and $59 \% \pm 11 \%, p<0.01$ and $p<0.05$, respectively) after overnight culture in $2 \%$ oxygen, a result consistent with exposure of cells to higher oxygen levels in aggregates than in islets (ANOVA $p<0.05$ ). Vegf and $i$ Nos expression levels were also lower $(88 \pm 19 \%$ and $37 \pm 30 \%$, respectively), although iNos significance might have been lost by variability. Beta cell genes Ins 1 and Glut 2 were also expressed at similar levels ( $135 \pm 25 \%$ and $165 \pm 61 \%$ ). These results for non-encapsulated islets and aggregates can be extrapolated to islet tissue encapsulated in the microcapsules used here because the oxygen supply limitation is associated primarily with consumption and diffusion in the islet tissue [17, 18] and the additional diffusion resistance in these capsules would simply add to these effects.

Necrosis in transplanted encapsulated islets Two weeks after encapsulated islets and aggregates were transplanted into syngeneic (Lewis rat) recipients, large areas of central necrosis were apparent in many of the islets and were especially prominent in the larger islets (Fig. 4). In contrast, encapsulated aggregates remained healthy in appearance.

Superior performance of encapsulated aggregates in marginal mass transplantations to diabetic mouse recipients A volume of encapsulated Sprague-Dawley rat islet tissue that would cure some but not all diabetic mouse recipients was determined in preliminary transplant experiments with ICR/SCID mice. Transplants with encapsulated aggregates of 375,250 and 125 IE successfully reversed diabetes in all mice (data in ESM). Transplants of aggregates of $125 \mathrm{IE}$ demonstrated durability for at least 56 days, and intraperitoneal glucose tolerance tests (IPGTTs) showed that the beta cells remained responsive to glucose at this time. A marginal transplant mass of 85 IE (determined by nuclei counting) was chosen for streptozotocin-induced diabetic $\mathrm{BALB} / \mathrm{c}$ mice. Encapsulated aggregates cured a greater proportion of recipients (83\%) compared with encapsulated

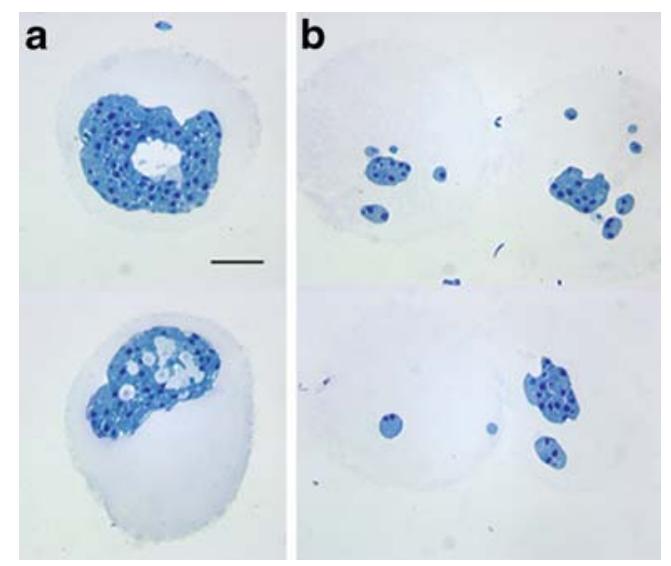

Fig. 4 Plastic sections of capsules stained with Toluidine Blue after 2 week syngeneic transplantation in non-diabetic Lewis rats: a islets and b aggregates. The islets show cell death (pale areas) and loss of core tissue. The aggregates remain viable in appearance. Scale bar, $50 \mu \mathrm{m}$ 
islets $(30 \%)(p<0.03$, Fisher exact test; Fig. 5a,b), and the overall average blood glucose concentration was substantially lower with encapsulated aggregates. In IPGTTs performed on cured transplant recipients, aggregates were as responsive as islets to a glucose load in terms of insulin secretion. Glucose clearance was similar to the normoglycaemic controls (Fig. 5c).

\section{Discussion}

Islet cell aggregates are a promising alternative to whole islets for transplantation and reversal of diabetes. This should also be true for beta cells generated from expansion, xenogeneic sources or stem/progenitor cells, because the success of aggregates over whole islets lies simply in the dimensions of the tissue configuration, with smaller aggregates proving more viable and functional in lowoxygen conditions than larger islets because the magnitude of the oxygen gradient is reduced. Encapsulated islet cell aggregates are superior to intact islets in their ability to survive and function in a low-oxygen environment in vitro and following transplantation. In this study, we cultured encapsulated islet tissue on silicone rubber membranes so as to make the $p \mathrm{O}_{2}$ to which the capsules were exposed about the same as in the gas phase [28]. The low-oxygenconcentration culture conditions were chosen to approximate the levels of hypoxia expected to be present in encapsulated non-vascularised islets or islet cell aggregates. These levels have been predicted to impair secretion and viability of centrally located cells within such islets or aggregates of islet cells [12, 17-19, 24].
Histological sections of encapsulated whole islets after culture in $2 \%$ oxygen or transplantation showed central necrosis in islets but rarely in the smaller aggregates. Various tests of islet viability and function are performed after encapsulated islets and aggregates are cultured in low oxygen, including OCR, tissue recovery, insulin:DNA ratio and GSIS. In all of these, aggregates have better outcomes than whole islets, but there are interesting differences. Because each of these measurements is an assessment of a different but important variable of health, it is not surprising that they would be affected at different oxygen levels. Results of OCR are more dramatic than those for nuclei recovery, which may be explained by the persistence of nuclei in hypoxic cells that may or may not be moribund. GSIS is dysfunctional in the low-oxygen environment with both tissue configurations. Insulin secretion is more impaired at higher oxygen levels than is tissue viability [12]. Consequently, some cells can lose function but still remain viable. The insulin:DNA ratio is a measure of tissue viability because a major function of healthy beta cells is to store insulin. The ability to store insulin also remains more intact at lower oxygen levels than does regulated insulin secretion. The important conclusion from all these viability variables is that when hypoxia causes detrimental effects on any of these measurements, it is always more severe for intact islets than aggregates.

The process of dispersion, aggregation and culture prior to encapsulation results in loss of a significant proportion of islet tissue $(45 \pm 7 \%)$, which is somewhat larger than the $35 \%$ loss of viable tissue observed with intact rat islets [26]. This small difference is outweighed by the gain in terms of superior viability $(100 \%$ vs $61 \%$ of OCR recovery after $2 \%$

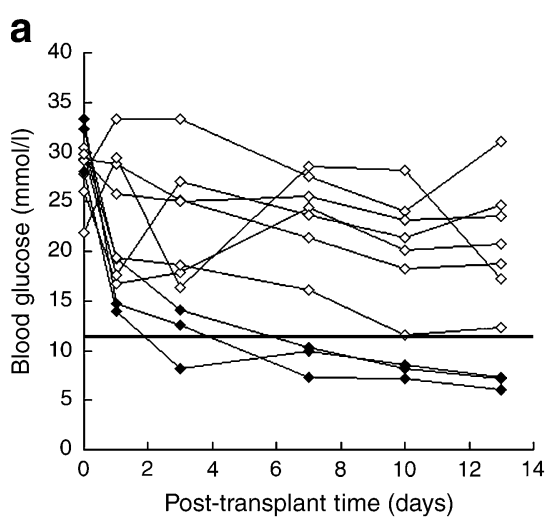

Fig. 5 Blood glucose concentrations in diabetic BALB/c mice following intraperitoneal transplantation of encapsulated SpragueDawley rat islets (85 IE) (a) or aggregates (85 IE) (b). Cure (two consecutive glucose measurements below $11.2 \mathrm{mmol} / \mathrm{l}$ ) was reached more often in aggregate-capsule recipients $(10 / 12)$ than in isletcapsule recipients $(3 / 10), p<0.03$, Fisher exact test. Overall average blood glucose concentrations for cured transplant recipients at days 7 , 10 and 13 post-transplant were significantly lower for aggregate
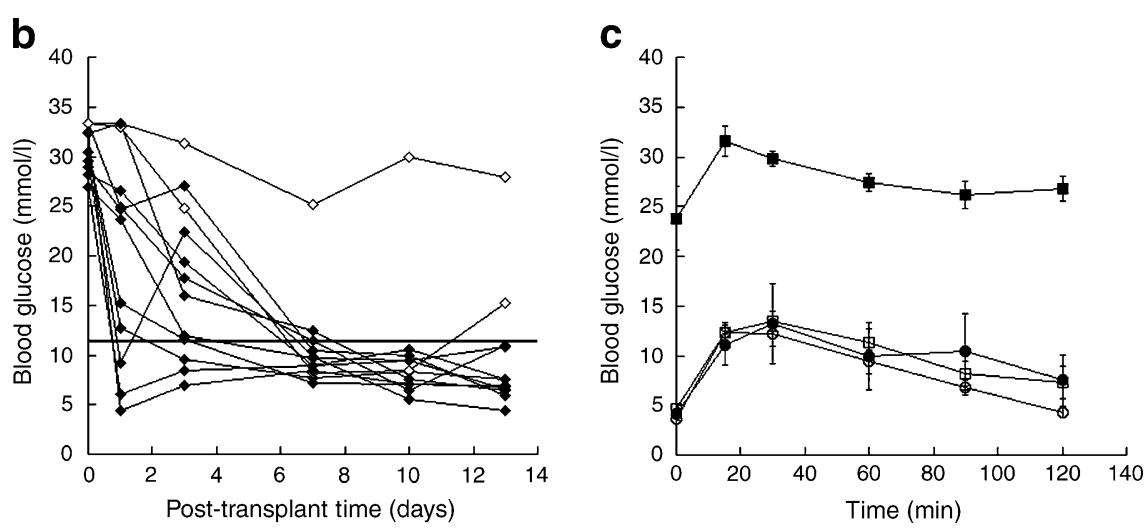

recipients, than for islet recipients respectively. c IPGTT results showing glucose concentrations before (time 0 ) and 15, 30, 60, 90 and $120 \mathrm{~min}$ after injection of glucose $(2 \mathrm{mg} / \mathrm{g}$ body weight). Average blood glucose results for cured recipients of encapsulated islets (black circles, $n=3$ ) or encapsulated aggregates (white circles, $n=10$ ) are compared with normoglycaemic (white squares, $n=3$ ) and hyperglycaemic diabetic (black squares, $n=2$ ) controls 
oxygen culture (Fig. 2c)). Experimental data (Fig. 3b) and simulation with a theoretical model reveals that the loss in insulin-secretory function resulting from hypoxia can be substantially reduced with aggregates, and the net effect of using aggregates instead of islets can be an important increase in the efficiency of utilisation of the original islet tissue (see ESM).

Aggregate-containing microcapsules can successfully reverse diabetes in a marginal mass under conditions where most whole-islet-containing microcapsules fail to reverse diabetes. The likely reason for greater success with aggregates is that they are exposed to higher oxygen levels than inner cells of whole islets. This will predictably lead to lower levels of cell death and better insulin secretion from aggregates. Another potential contributor to improved aggregate-transplantation success is reduced release of pro-inflammatory hypoxia-dependent cytokines and cell debris from the capsules, which could reduce host immune responses. $M c p-1$ and the gene encoding tissue factor (F3) are expressed at lower levels in the aggregates after hypoxic culture. Release of these factors from islets prior to transplantation negatively correlates with the success of clinical islet transplantation [13, 29]. Expression of iNos and Vegf, which is known to be upregulated in islets under hypoxia $[14,30]$, is also reduced in aggregates; for $i N o s$, a lack of significance may have been missed because of experimental variability.

Human islet tissue is problematic because of its poor viability and limited supply. A major goal for the field is to find a renewable source of islet cells to address the current severe shortage [4]. Once a source becomes available, the principles of the current study should be applied to produce aggregates of an ideal size that will maximise tissue survival and function and limit the release of cytokines and antigens. Another benefit of islet cell aggregates compared with whole islets is that their superior survival should allow greater packing density, which becomes especially important if immunoprotection is needed and planar-type subcutaneous devices are used. The use of aggregates should reduce the overall surface required for surgical implantation and retrieval.

In conclusion, encapsulated islet cell aggregates survive and function better than encapsulated whole islets in lowoxygen environments and when transplanted. These findings have important implications for future developments in clinical cell transplantation in general and beta cell replacement therapy for diabetes in particular.

Acknowledgements This research was supported by RO1 DK 50657 from the NIH, the Juvenile Diabetes Research Foundation, the Diabetes Research and Wellness Foundation and the Advanced Microscopy Cores of the Joslin Diabetes and Endocrinology Research Center (DERC grant, DK 36836). E. S. O'Sullivan was the recipient of a travelling studentship from the National University of Ireland. Advice on real-time RT-PCR was received from A. Vetere, W-C. Li and J. Thorne. Biospherix provided the Xvivo for use in these experiments.

Duality of interest The authors declare that there is no duality of interest associated with this manuscript.

\section{References}

1. Lim F, Sun AM (1980) Microencapsulated islets as bioartificial endocrine pancreas. Science 210:908-910

2. Duvivier-Kali VF, Omer A, Parent RJ, O'Neil JJ, Weir GC (2001) Complete protection of islets against allorejection and autoimmunity by a simple barium-alginate membrane. Diabetes 50:1698-1705

3. Colton CK (1995) Implantable biohybrid artificial organs. Cell Transplant 4:415-436

4. Bonner-Weir S, Weir GC (2005) New sources of pancreatic betacells. Nat Biotechnol 23:857-861

5. Kroon E, Martinson LA, Kadoya K et al (2008) Pancreatic endoderm derived from human embryonic stem cells generates glucoseresponsive insulin-secreting cells in vivo. Nat Biotechnol 26:443-452

6. Lee SH, Hao E, Savinov AY, Geron I, Strongin AY, Itkin-Ansari P (2009) Human beta-cell precursors mature into functional insulinproducing cells in an immunoisolation device: implications for diabetes cell therapies. Transplantation 87:983-991

7. De Vos P, van Straaten JFM, Nieuwenhuizen AG et al (1999) Why do microencapsulated islet grafts fail in the absence of fibrotic overgrowth. Diabetes 48:1381-1388

8. Davalli AM, Ogawa Y, Ricordi C, Scharp DW, Bonner-Weir S, Weir GC (1995) A selective decrease in the beta cell mass of human islets transplanted into diabetic nude mice. Transplantation 59:817-820

9. MacGregor RR, Williams SJ, Tong PY, Kover K, Moore WV, Stehno-Bittel L (2006) Small rat islets are superior to large islets in in vitro function and in transplantation outcomes. Am J Physiol Endocrinol Metab 290:E771-E779

10. Lehmann R, Zuellig RA, Kugelmeier P et al (2007) Superiority of small islets in human islet transplantation. Diabetes 56:594-603

11. Avgoustiniatos ES, Colton CK (1997) Effect of external oxygen mass transfer resistances on viability of immunoisolated tissue. Ann N Y Acad Sci 831:145-167

12. Dionne KE, Colton CK, Yarmuch ML (1993) Effect of hypoxia on insulin secretion by isolated rat and canine islets of Langerhans. Diabetes 42:12-21

13. Bertuzzi F, Marzorati S, Maffi P et al (2004) Tissue factor and CCL2/monocyte chemoattractant protein-1 released by human islets affect islet engraftment in type 1 diabetic recipients. J Clin Endocrinol Metab 89:5724-5728

14. de Groot M, Schuurs TA, Keizer PP, Fekken S, Leuvenink HG, van Schilfgaarde R (2003) Response of encapsulated rat pancreatic islets to hypoxia. Cell Transplant 12:867-875

15. Halban PA, Powers SL, George KL, Bonner-Weir S (1987) Spontaneous reassociation of dispersed adult rat pancreatic islet cells into aggregates with 3-dimensional architecture typical of native islets. Diabetes 36:783-791

16. King AJ, Fernandes JR, Hollister-Lock J, Nienaber CE, Bonner-Weir S, Weir GC (2007) Normal relationship of beta- and non-beta-cells not needed for successful islet transplantation. Diabetes 56:2312-2318

17. Johnson AS, Fisher RJ, Weir GC, Colton GC (2009) Oxygen consumption and diffusion in assemblages of respiring spheres: performance enhancement of a bioartificial pancreas. Chem Eng Sci 64:4470-4487

18. Lewis AS, Fisher RJ, Weir GC, Colton CK (2009) Improving oxygen supply to encapsulated cells and islets. In: Halle JP, de Vos $\mathrm{P}$, Rosenberg L (eds) The bioartifical pancreas and other hybrid therapies. Transworld Research Network, Kerala, pp 205-241 
19. Lewis AS (2008) Eliminating oxygen supply limitations for transplanted microencapsulated islets in the treatment of type 1 diabetes. Ph.D. thesis, Massachusetts Institute of Technology, Cambridge, MA, USA

20. Gotoh M, Maki T, Kiyoizumi T, Satomi S, Monaco AP (1985) An improved method for isolation of mouse pancreatic islets. Transplantation 40:437-438

21. Rappel MJ (2007) Maintaining islet quality during culture. Ph.D. thesis, Massachusetts Institute of Technology, Cambridge, MA, USA

22. Papas KK, Pisania A, Wu H, Weir GC, Colton CK (2007) A stirred microchamber for oxygen consumption rate measurements with pancreatic islets. Biotechnol Bioeng 98:1071-1082

23. Papas KK, Avgoustiniatos ES, Tempelman LA et al (2005) Highdensity culture of human islets on top of silicone rubber membranes. Transplant Proc 37:3412-3414

24. Avgoustiniatos ES (2001) Oxygen diffusion limitaitons in pancreatic islet culture and immunoisolation. Ph.D. thesis, Massachusetts Institute of Technology, Cambridge, MA, USA
25. Halle JP, Landry D, Fournier A, Beaudry M, Leblond FA (1993) Method for the quantification of alginate in microcapsules. Cell Transplant 2:429-436

26. Pisania A (2007) Development of quantitative methods for quality assessment of islets of Langerhans. Ph.D. thesis, Massachusetts Institute of Technology, Cambridge, MA, USA

27. Papas KK, Colton CK, Qipo A, Wu H, Nelson RA, Hering BJ, Weir GC, Koulmanda M (2009) Prediction of marginal mass required for successful islet transplantation. J Invest Surg 22:1-7

28. Powers DE, Millman JR, Bonner-Weir S, Rappel MJ, Colton CK (2010) Accurate control of oxygen level in cells during culture on silicone rubber membranes with application to stem cell differentiation. Biotechnol Progr (in press)

29. Bertuzzi F, Ricordi C (2007) Prediction of clinical outcome in islet allotransplantation. Diabetes Care 30:410-417

30. Vasir B, Aiello LP, Yoon KH, Quickel RR, Bonner-Weir S, Weir GC (1998) Hypoxia induces vascular endothelial growth factor gene and protein expression in cultured rat islet cells. Diabetes 47:1894-1903 